\title{
Interleukin gene polymorphisms in Chinese Han population with breast cancer, a case-control study
}

\author{
Xiaoxiao Zuo ${ }^{1, *}$, Miao $\mathrm{Li}^{2, *}$, Ya Yang ${ }^{1}$, Tiansong Liang ${ }^{1}$, Hongyao Yang ${ }^{1}$, Xinhan \\ Zhao $^{2}$ and Daoke Yang ${ }^{1}$ \\ ${ }^{1}$ Department of Radiation Oncology, First Affiliated Hospital of Zhengzhou University, Zhengzhou, Henan Province 450000, \\ People's Republic of China \\ ${ }^{2}$ Department of Internal Medicine Oncology, The Fifth People's Hospital of Qinghai Province, Xining, Qinghai 810007, China \\ *These authors contribute equally to this work \\ Correspondence to: Daoke Yang, email: ydk8666@126.com \\ Xinhan Zhao, email: zhaoxinhan@mail.xjtu.edu.cn
}

Keywords: cytokines; IL 1; breast cancer; case-control; polymorphisms

Received: September 06, 2017 Accepted: November 15, 2017 Epub: December 11, 2017 Published: April 06, 2018

Copyright: Zuo et al. This is an open-access article distributed under the terms of the Creative Commons Attribution License 3.0 (CC BY 3.0), which permits unrestricted use, distribution, and reproduction in any medium, provided the original author and source are credited.

\section{ABSTRACT}

Cytokines are known as important regulators of the cancer involved in inflammatory and immunological responses. This fact and plethora of gene polymorphism data prompted us to investigate IL1 gene polymorphisms in breast cancer (BC) patients. Totally, 530 patients with BC and 628 healthy control women were studied. The genetic polymorphisms for IL1 were analyzed by Massarray Sequencing method. Three single nucleotide polymorphisms (SNPs) identified in IL1B, IL1R1 gene are thought to influence breast cancer risk. The results of the association between IL-1B, IL1R1 polymorphisms and breast cancer risk have significant. We found that the variant TT genotype of rs10490571 was associated with a significantly increased breast cancer risk (TT vs. CC: $O R=2.82,95 \% C I=1.12-7.08, P=0.047$ for the codominant model). For rs16944 (AG vs. GG: OR $=0.60,95 \%$ CI $=0.41-0.90$, $P=0.034$ for the codominant model) and rs1143623 (CG vs. CC: OR $=0.65,95 \%$ CI $=0.45-0.94, P=0.023$ for the codominant model) have significant associations were found in genetic models. In conclusion, the present analysis suggests a correlation of polymorphic markers within the IL-1 gene locus with the risk in developing breast cancer. Taken together with our finding that IL1B, IL1R1 gene three SNP are also associated with the risk for the disease, we suggest that inflammation via innate and adaptive immunity contributes to multifactorial hereditary predisposition to pathogenesis of the breast cancer.

\section{INTRODUCTION}

Breast cancer $(\mathrm{BC})$ is one of the most common causes of cancer death in women and one of the important factors contributing to the whole world health burden [1]. Currently, routine BC clinical management depended on few well-defined biologicalmarkers and clinicopathological variables. Mutations in BRCA1, BRCA2 gene is inherited in an autosomal dominant manner and possess highly risky [2, 3] however, account for only a small percentage of $\mathrm{BC}$ cases [4]. It is very likely that a number of low penetrance genes conduce to $\mathrm{BC}$ susceptibility, thereby accounting for a higher proportion of the disease burden $[5,6]$.

The role of cytokines in cancer immunization and carcinogenesis has been recognized [7]. Many studies of cytokine polymorphisms associated with susceptibility to $[8,9]$, liver cancer $[10,11]$, lung cancer [12], prostate cancer [13] and ovarian cancer [14] are mixed.

Interleukin (IL) - 1 is an endogenous cytokine family involved in inflammation and immune response, including IL-1 alpha (IL-1A), IL-1 beta (IL-1B) and IL-1 receptor 
Table 1: Basic characteristic of patients with breast cancer and the control individuals

\begin{tabular}{|c|c|c|c|}
\hline Characteristics & Cases $(N=530)$ & Controls $(N=628)$ & $p$-value \\
\hline Age & & & 0.211 \\
\hline Mean $\pm \mathrm{SD}$ & $50.69 \pm 11.74$ & $51.04 \pm 9.64$ & \\
\hline Menopause & & & 0.909 \\
\hline Premenopausal & $216(40.8 \%)$ & $258(41.1 \%)$ & \\
\hline Postmenopausal & $314(59.2 \%)$ & $370(58.9 \%)$ & \\
\hline \multicolumn{4}{|l|}{ Clinical Stages } \\
\hline I & $232(43.8 \%)$ & & \\
\hline II/III/IV & $298(56.2 \%)$ & & \\
\hline \multicolumn{4}{|l|}{ Estrogen Receptor } \\
\hline Negative & $220(41.5 \%)$ & & \\
\hline Positive & $310(58.5 \%)$ & & \\
\hline \multicolumn{4}{|c|}{ Progestrone Receptor } \\
\hline Negative & $278(52.5 \%)$ & & \\
\hline Positive & $252(47.5 \%)$ & & \\
\hline \multicolumn{4}{|l|}{ HER2 } \\
\hline Negative & $208(39.2 \%)$ & & \\
\hline Positive & $322(60.8 \%)$ & & \\
\hline
\end{tabular}

antagonist (IL-1Ra) encoded by IL-1RN [15]. IL-1 is one of the major proinflammatory cytokines that increases in cancer patients [16]. In many tumor types, IL-1 is thought to be up-regulated and is expressed as a factor in tumor progression by metastasis and expression of angiogenic genes and growth factors.

Many studies have reported that high IL-1 concentrations in the tumor microenvironment are associated with more toxic tumor phenotypes. For example, in solid tumors, IL-1 has been shown to be upregulated, including melanoma, colon cancer, lung cancer, head and neck cancer, and patients with high IL-1 producing tumours have generally bad prognoses $[17,18]$. IL-1 has been recently suggested to play a role in the development of breast cancer. Multifunctional cytokines are closely related to the development of inflammatory and immunological responses which play a key role in the pathogenesis of autoimmune and malignant diseases [7, 19], making them an important candidate genes in $\mathrm{BC}$. Considering the diverse roles of cytokines in cell growth, proliferation, differentiation and migration in inflammation and cancers, we proposed that polymorphisms in the cytokine genes could affect the risk of BC. Therefore the present study, we attempt to investigate the selected SNPs possible correlations the BC risk in Han Chinese population.

\section{RESULTS}

This hospital-based case-control study consisted of 530 patients and 628 healthy age-matched controls. Of the total 1158 breast cancer cases, the age of the case subjects was $50.69 \pm 11.74$, the control was $51.04 \pm 9.64$. Based on menopause status,

$40.8 \%$ cases were premenopausal, $59.2 \%$ cases were postmenopausal. $43.8 \%$ cases were in stages I and $56.2 \%$ were II, III and IV. Of these cases, 41.5\%, 58.5\% belonged to $\mathrm{ER}^{-}, \mathrm{ER}^{+}$, respectively. $\mathrm{PR}^{-}, \mathrm{PR}^{+}$is $52.5 \%, 47.5 \%$ respectively. Information on status of HER2 expression, $39.2 \%$ cases were negative, and $60.8 \%$ were positive (Table 1).

The allele and genotype frequencies of IL-1 in the healthy and case groups are shown in Table 2. The control group genotype data for all SNPs were analyzed for fitness in Hardy Weinberg equilibrium with no significant deviation observed in any case. From this table it can be seen that, while no significant allel associations were demonstrated for any SNP. From Table 3, the ageadjusted ORs estimated by a logistic model are shown three SNPs: IL1R1 (rs10490571), IL1B (rs16944, rs1143623) had significant in BC risk. For rs 10490571, the estimates relative to the TT genotype were $2.63(95 \% \mathrm{CI}$, 1.05-6.55) for the CC/CT genotype. The rs16944 (A/G) polymorphism was positively associated with the risk of $\mathrm{BC}$ in codominant $(\mathrm{OR}=0.60,95 \% \mathrm{CI}=0.41-0.90$; $P=0.034)$, Dominant $(\mathrm{OR}=0.67,95 \% \mathrm{CI}=0.46-0.97$; $P=0.035)$. There was significant association between the rs $1143623 \mathrm{C} / \mathrm{G}$ allele and $\mathrm{BC}$ patients compared to the healthy controls in codominant model $(\mathrm{OR}=0.65,95 \%$ $\mathrm{CI}=0.45-0.94 ; P=0.023)$.

From the stratification analyses, it was found that in Table 4 BC risk associated with rs $10490571 \mathrm{~T} / \mathrm{C}$ variant was more evident in postmenopausal women $(\mathrm{OR}=1.46$ $95 \% \mathrm{CI}=1.04-2.04, P=0.029)$. $\mathrm{ER}^{+}$women three SNPs 
Table 2: Basic information of candidate SNPs in this study

\begin{tabular}{|c|c|c|c|c|c|c|c|c|c|}
\hline \multirow{2}{*}{ SNP } & \multirow{2}{*}{ Gene } & \multirow{2}{*}{ Chr } & \multirow{2}{*}{ Allels(A/B) } & \multirow{2}{*}{ p-HWE } & \multicolumn{2}{|c|}{ MAF } & \multirow{2}{*}{ OR } & \multirow{2}{*}{$95 \% \mathrm{CI}$} & \multirow{2}{*}{$P$} \\
\hline & & & & & Case & Control & & & \\
\hline rs11674595 & IL1R2 & $2 \mathrm{q} 11.2$ & $\mathrm{C} / \mathrm{T}$ & 0.408 & 0.289 & 0.243 & 1.16 & $0.88-1.53$ & 0.217 \\
\hline rs4851527 & IL1R2 & $2 \mathrm{q} 11.2$ & $\mathrm{~A} / \mathrm{G}$ & 0.697 & 0.382 & 0.296 & 0.89 & $0.70-1.15$ & 0.320 \\
\hline rs 719250 & IL1R2 & $2 \mathrm{q} 11.2$ & $\mathrm{~T} / \mathrm{C}$ & 0.103 & 0.365 & 0.269 & 0.89 & $0.69-1.15$ & 0.293 \\
\hline rs3218896 & IL1R2 & $2 \mathrm{q} 11.2$ & $\mathrm{C} / \mathrm{T}$ & 0.478 & 0.997 & 0.136 & 1.00 & $0.71-1.40$ & 0.136 \\
\hline rs3218977 & IL1R2 & $2 \mathrm{q} 11.2$ & $\mathrm{G} / \mathrm{A}$ & 0.357 & 0.532 & 0.226 & 0.92 & $0.70-1.20$ & 0.242 \\
\hline rs2072472 & IL1R2 & $2 \mathrm{q} 11.2$ & $\mathrm{G} / \mathrm{A}$ & 0.129 & 0.224 & 0.243 & 1.19 & $0.90-1.56$ & 0.213 \\
\hline rs 10490571 & IL1R1 & $2 q 12.1$ & $\mathrm{~T} / \mathrm{C}$ & 0.549 & 0.026 & 0.219 & 1.40 & $1.04-1.87$ & 0.167 \\
\hline rs956730 & IL1R1 & $2 q 12.1$ & $\mathrm{~A} / \mathrm{G}$ & 0.352 & 0.729 & 0.230 & 0.95 & $0.73-1.25$ & 0.239 \\
\hline rs3917225 & IL1R1 & $2 \mathrm{q} 12.1$ & $\mathrm{~T} / \mathrm{C}$ & 0.716 & 0.217 & 0.400 & 1.16 & $0.92-1.47$ & 0.365 \\
\hline rs3917318 & IL1R1 & $2 q 12.1$ & $\mathrm{G} / \mathrm{A}$ & 0.910 & 0.054 & 0.442 & 0.80 & $0.63-1.00$ & 0.498 \\
\hline rs 3783550 & IL1A & $2 q 13$ & $\mathrm{~T} / \mathrm{G}$ & 0.532 & 0.612 & 0.357 & 1.06 & $0.84-1.36$ & 0.342 \\
\hline rs3783546 & IL1A & $2 q 13$ & $\mathrm{C} / \mathrm{G}$ & 0.532 & 0.612 & 0.357 & 1.06 & $0.84-1.36$ & 0.342 \\
\hline rs2856838 & IL1A & $2 q 13$ & $\mathrm{~A} / \mathrm{G}$ & 0.875 & 0.106 & 0.275 & 1.24 & $0.95-1.62$ & 0.234 \\
\hline rs 1609682 & IL1A & $2 q 13$ & $\mathrm{~T} / \mathrm{G}$ & 0.532 & 0.593 & 0.357 & 1.07 & $0.84-1.36$ & 0.342 \\
\hline rs 3783521 & IL1A & $2 q 13$ & $\mathrm{G} / \mathrm{A}$ & 0.532 & 0.612 & 0.357 & 1.06 & $0.84-1.36$ & 0.342 \\
\hline rs 2853550 & IL1B & $2 q 13$ & $\mathrm{~A} / \mathrm{G}$ & 0.318 & 0.996 & 0.092 & 1.00 & $0.67-1.49$ & 0.092 \\
\hline rs1143643 & IL1B & $2 q 13$ & $\mathrm{C} / \mathrm{T}$ & 0.910 & 0.427 & 0.462 & 0.91 & $0.72-1.15$ & 0.486 \\
\hline rs3136558 & IL1B & $2 q 13$ & $\mathrm{G} / \mathrm{A}$ & 0.480 & 0.593 & 0.381 & 0.94 & $0.74-1.19$ & 0.396 \\
\hline rs 1143630 & IL1B & $2 q 13$ & $\mathrm{~T} / \mathrm{G}$ & 0.176 & 0.581 & 0.166 & 0.92 & $0.67-1.25$ & 0.178 \\
\hline rs1143627 & IL1B & $2 q 13$ & $\mathrm{G} / \mathrm{A}$ & 0.142 & 0.488 & 0.519 & 1.09 & $0.86-1.37$ & 0.498 \\
\hline rs16944 & IL1B & $2 q 13$ & $\mathrm{~A} / \mathrm{G}$ & 0.114 & 0.405 & 0.475 & 0.91 & $0.72-1.14$ & 0.500 \\
\hline rs 1143623 & IL1B & $2 q 13$ & $\mathrm{G} / \mathrm{C}$ & 0.132 & 0.746 & 0.409 & 0.96 & $0.76-1.22$ & 0.419 \\
\hline
\end{tabular}

Abbreviations: SNP: single nucleotide polymorphism, Alleles A/B: Minor/major alleles; MAF, minor allele frequency; OR: odds ratio, CI: confidence interval, HWE: Hardy-Weinberg equilibrium.

$p \leq 0.05$ indicates statistical significance.

$(\mathrm{rs} 10490571, \mathrm{OR}=1.4895 \% \mathrm{CI}=1.06-2.07, P=0.023$; rs $1143627, \mathrm{OR}=1.3895 \% \mathrm{CI}=1.05-1.81, P=0.023$; rs16944, OR $=0.73,95 \% \mathrm{CI}=0.56-0.96, P=0.026$ ) were associated with $\mathrm{BC}$ risk. It is evident that statistically significant association exists between rs10490571, rs3917318, rs2856838, rs1143627, rs16944 polymorphism and $\mathrm{BC}$ risk in $\mathrm{PR}+$ women. With regard to HER2 status, the difference was significant, the OR among HER2+ women was $1.59(1.15-2.22)$ for rs $10490571,0.72(0.55$ 0.94 ) for rs3917318 were associated with BC risk, whereas that for HER2- women there was no significant SNPs.

Among controls, this SNP was found to be in high LD in IL1A and IL1B (all pairwise $r^{2}>0.80$ ) in Figure 1. The association between the IL1A and IL1B haplotype and the risk of $\mathrm{BC}$ were analysised, however, we did not find any statistical evidence for the risk of breast cancer in our study.

\section{DISCUSSION}

In this study, we focused on a possible inflammation role, we investigated the association of twenty-two polymorphisms in IL1A, IL1B, IL1R1 and IL1R2 gene with $\mathrm{BC}$ in 530 patient compared to628 normal women as the control group. Our results suggested that rs 10490571 in IL1R1 and rs16944, rs1143623 in IL1B were associated with $\mathrm{BC}$ risk in Chinese Han population.

Cytokines are small molecules secreted by cells in response to specific stimuli and change the behavior of the same or other cells. Multifunctional cytokines are closely related to the development of inflammatory and immunological responses which play a key role in the pathogenesis of autoimmune and malignant diseases, making them important candidate genes in $\mathrm{BC}[20,21]$. The single nucleotide polymorphisms in a particular candidate gene are thought to affect the expression and / or activity of the encoded protein, thereby inducing solid cancer, particularly breast cancer [22]. The polymorphism of the cytokine gene regulatory region may alter its expression level associated with the immune response $[23,24]$. IL-1 family of cytokines is encoded by two separate genes, IL1A and IL1B are located within a 430 $\mathrm{kb}$ region on chromosome $2 \mathrm{q} 14.2$ in a cluster and also contains the genes for IL1 receptors type 1 and 2 (IL1R1 
Table 3: Logistic regression analysis of the association between the IL1 SNPs and breast cancer risk

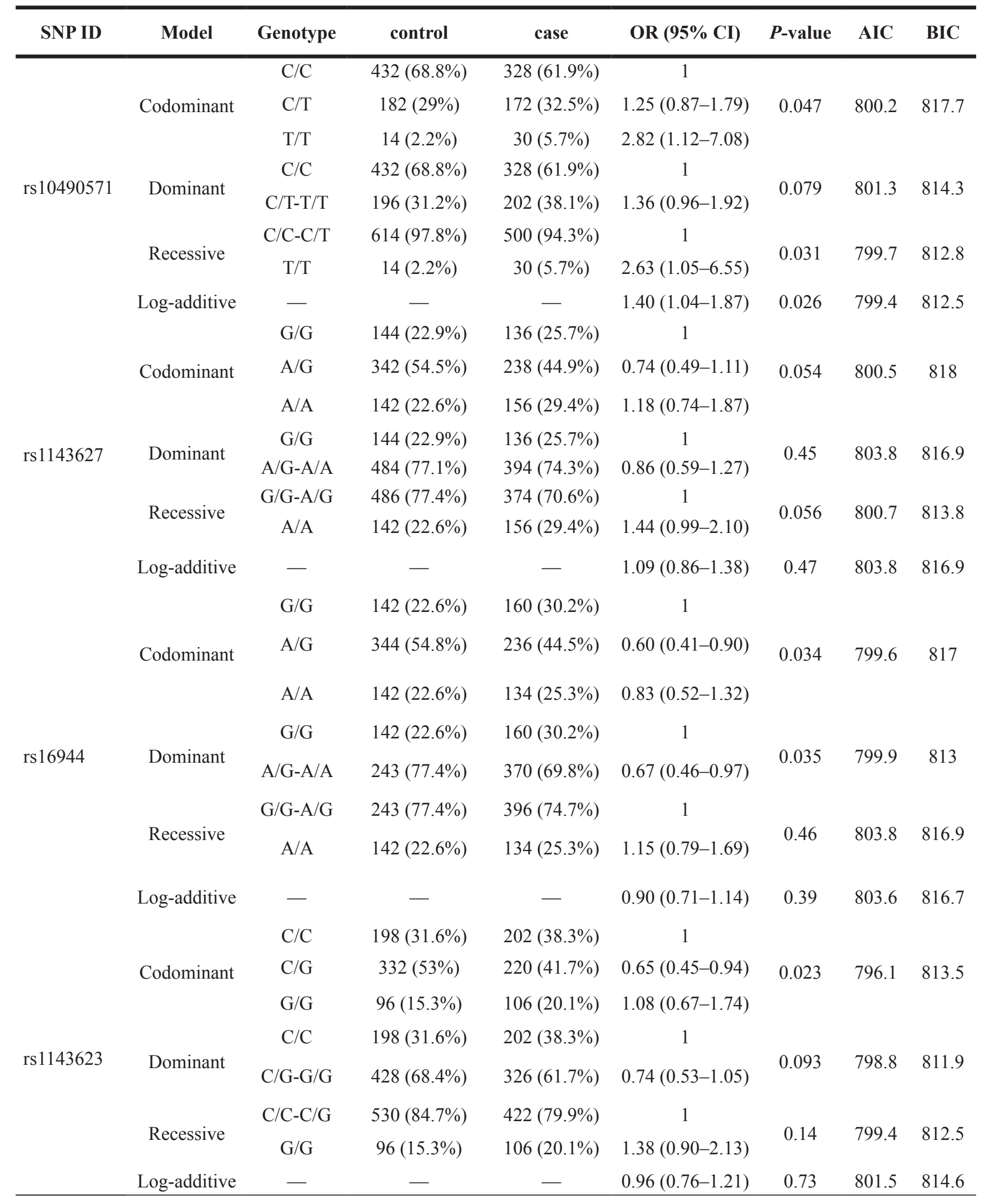

Abbreviations: OR: odds ratio, CI: confidence interval AIC: Akaike’s Information criterion; BIC: Bayesian Information criterion.

${ }^{*} p$ value $<0.05$ indicates statistical significance. 
Table 4: Logistic regression analysis of the association between the IL1 SNPs and breast cancer risk by stratification analysis

\begin{tabular}{|c|c|c|c|c|c|c|c|c|c|c|c|c|c|c|c|c|c|c|c|c|c|c|c|c|}
\hline \multirow{2}{*}{ SNP ID } & \multicolumn{3}{|c|}{ Premenopausal } & \multicolumn{3}{|c|}{ Postmenopausal } & \multicolumn{3}{|c|}{ ER+ } & \multicolumn{3}{|c|}{ ER- } & \multicolumn{3}{|c|}{ PR+ } & \multicolumn{3}{|c|}{ PR- } & \multicolumn{3}{|c|}{ HER2+ } & \multicolumn{3}{|c|}{ HER2- } \\
\hline & OR & $95 \% \mathrm{Cl}$ & $P$ & OR & $95 \% \mathrm{CI}$ & $P$ & $\mathrm{OR}$ & $95 \% \mathrm{CI}$ & $P$ & OR & $95 \% \mathrm{CI}$ & $P$ & OR & $95 \% \mathrm{CI}$ & $P$ & OR & $95 \% \mathrm{CI}$ & $P$ & OR & $95 \% \mathrm{CI}$ & $P$ & OR & $95 \% \mathrm{CI}$ & $P$ \\
\hline rs11674595 & 1.29 & $0.90-1.85$ & 0.158 & 1.07 & $0.78-1.49$ & 0.670 & 1.17 & $0.85-1.62$ & 0.334 & 1.14 & $0.8-1.65$ & 0.465 & 1.15 & $0.82-1.63$ & 0.422 & 1.17 & $0.84-1.63$ & 0.361 & 1.19 & $0.87-1.64$ & 0.275 & 1.11 & $0.77-1.61$ & 0.577 \\
\hline rs4851527 & 0.76 & $0.54-1.08$ & 0.122 & 0.99 & $0.74-1.33$ & 0.961 & 0.92 & $0.69-1.24$ & 0.601 & 0.85 & $0.61-1.19$ & 0.353 & 0.93 & $0.68-1.28$ & 0.676 & 0.86 & $0.63-1.17$ & 0.332 & 0.89 & $0.66-1.19$ & 0.430 & 0.90 & $0.64-1.27$ & 0.554 \\
\hline rs719250 & 0.95 & $0.67-1.34$ & 0.767 & 0.85 & $0.62-1.15$ & 0.284 & 0.74 & $0.54-1.01$ & 0.056 & 1.13 & $0.81-1.57$ & 0.483 & 0.80 & $0.57-1.11$ & 0.180 & 0.98 & $0.71-1.33$ & 0.873 & 0.94 & $0.7-1.27$ & 0.706 & 0.80 & $0.56-1.15$ & 0.232 \\
\hline rs3218896 & 1.11 & $0.71-1.72$ & 0.651 & 0.93 & $0.62-1.39$ & 0.721 & 0.84 & $0.55-1.27$ & 0.399 & 1.25 & $0.82-1.9$ & 0.310 & 0.86 & $0.55-1.34$ & 0.506 & 1.13 & $0.76-1.69$ & 0.541 & 1.12 & $0.76-1.64$ & 0.577 & 0.83 & $0.51-1.35$ & 0.450 \\
\hline rs3218977 & 0.85 & $0.58-1.23$ & 0.384 & 0.97 & $0.7-1.33$ & 0.829 & 1.07 & $0.78-1.47$ & 0.669 & 0.72 & $0.49-1.06$ & 0.090 & 1.04 & $0.74-1.47$ & 0.804 & 0.81 & $0.57-1.14$ & 0.223 & 0.84 & $0.61-1.16$ & 0.286 & 1.04 & $0.73-1.5$ & 0.817 \\
\hline rs 2072472 & 1.26 & $0.88-1.81$ & 0.210 & 1.14 & $0.82-1.57$ & 0.437 & 1.14 & $0.82-1.57$ & 0.442 & 1.26 & $0.88-1.8$ & 0.208 & 1.15 & $0.81-1.63$ & 0.424 & 1.22 & $0.87-1.7$ & 0.246 & 1.28 & $0.94-1.75$ & 0.123 & 1.05 & $0.72-1.53$ & 0.813 \\
\hline rs10490571 & 1.31 & $0.89-1.94$ & 0.173 & 1.46 & $1.04-2.04$ & 0.029 & 1.48 & $1.06-2.07$ & 0.023 & 1.28 & $0.87-1.89$ & 0.212 & 1.73 & $1.22-2.46$ & 0.002 & 1.12 & $0.77-1.62$ & 0.550 & 1.59 & $1.15-2.22$ & 0.006 & 1.11 & $0.74-1.68$ & 0.607 \\
\hline rs12712127 & 1.24 & $0.87-1.78$ & 0.228 & 1.39 & $1.02-1,89$ & 0.038 & 1.34 & $0.98-1.84$ & 0.062 & 1.30 & $0.92-1.85$ & 0.140 & 1.57 & $1.14-2.18$ & 0.006 & 1.12 & $0.81-1.57$ & 0.490 & 1.52 & $1.12-2.06$ & 0.007 & 1.05 & $0.73-1.53$ & 0.780 \\
\hline rs956730 & 0.86 & $0.59-1.25$ & 0.437 & 1.02 & $0.74-1.4$ & 0.914 & 0.90 & $0.65-1.24$ & 0.506 & 1.04 & $0.73-1.48$ & 0.844 & 0.87 & $0.61-1.24$ & 0.435 & 1.03 & $0.74-1.43$ & 0.852 & 0.89 & $0.64-1.22$ & 0.458 & 1.06 & $0.74-1.53$ & 0.745 \\
\hline rs3917225 & 1.02 & $0.74-1.41$ & 0.880 & 1.26 & $0.96-1.67$ & 0.097 & 1.13 & $0.86-1.5$ & 0.390 & 1.21 & $0.88-1.65$ & 0.242 & 1.15 & $0.85-1.55$ & 0.372 & 1.18 & $0.88-1.57$ & 0.273 & 1.24 & $0.94-1.64$ & 0.122 & 1.05 & $0.76-1.45$ & 0.788 \\
\hline rs3917318 & 0.75 & $0.55-1.02$ & 0.066 & 0.83 & $0.63-1.09$ & 0.181 & 0.77 & $0.58-1.01$ & 0.057 & 0.84 & $0.62-1.14$ & 0.263 & 0.74 & $0.55-1$ & 0.048 & 0.85 & $0.64-1.12$ & 0.249 & 0.72 & $0.55-0.94$ & 0.016 & 0.93 & $0.68-1.28$ & 0.659 \\
\hline rs3783550 & 0.98 & $0.71-1.36$ & 0.906 & 1.13 & $0.85-1.49$ & 0.412 & 1.06 & $0.79-1.41$ & 0.706 & 1.08 & $0.78-1.48$ & 0.654 & 1.14 & $0.84-1.55$ & 0.389 & 1.00 & $0.74-1.34$ & 0.985 & 1.04 & $0.78-1.38$ & 0.792 & 1.11 & $0.8-1.53$ & 0.546 \\
\hline rs3783546 & 0.98 & $0.71-1.36$ & 0.906 & 1.13 & $0.85-1.49$ & 0.412 & 1.06 & $0.79-1.41$ & 0.706 & 1.08 & $0.78-1.48$ & 0.654 & 1.14 & $0.84-1.55$ & 0.389 & 1.00 & $0.74-1.34$ & 0.985 & 1.05 & $0.79-1.4$ & 0.720 & 1.08 & $0.78-1.5$ & 0.632 \\
\hline rs 2856838 & 1.17 & $0.82-1.67$ & 0.377 & 1.29 & $0.95-1.76$ & 0.099 & 1.26 & $0.92-1.71$ & 0.148 & 1.23 & $0.87-1.74$ & 0.251 & 1.39 & $1-1.92$ & 0.050 & 1.12 & $0.81-1.56$ & 0.489 & 1.25 & $0.92-1.7$ & 0.153 & 1.24 & $0.87-1.76$ & 0,245 \\
\hline rs1609682 & 0.97 & $0.7-1.35$ & 0.875 & 1.14 & $0.86-1.51$ & 0.374 & 1.07 & $0.8-1.42$ & 0.655 & 1.07 & $0.78-1.48$ & 0.680 & 1.16 & $0.85-1.57$ & 0.346 & 0.99 & $0.74-1.34$ & 0.959 & 1.06 & $0.8-1.41$ & 0.692 & 1.08 & $0.78-1.5$ & 0.632 \\
\hline rs 3783521 & 0.98 & $0.71-1.36$ & 0.906 & 1.13 & $0.85-1.49$ & 0.412 & 1.06 & $0.79-1.41$ & 0.706 & 1.08 & $0.78-1.48$ & 0.654 & 1.14 & $0.84-1.55$ & 0.389 & 1.00 & $0.74-1.34$ & 0.985 & 1.05 & $0.79-1.4$ & 0.720 & 1.08 & $0.78-1.5$ & 0.632 \\
\hline rs2853550 & 0.95 & $0.55-1.63$ & 0.847 & 1.04 & $0.65-1,65$ & 0.874 & 0.90 & $0.56-1.46$ & 0.669 & 1.15 & $0.69-1.91$ & 0.597 & 0.85 & $0.5-1,44$ & 0.540 & 1.14 & $0.72-1.83$ & 0.573 & 0.90 & $0.56-1.45$ & 0.664 & 1.16 & $0.69-1.95$ & 0.569 \\
\hline rs1 1143643 & 1.02 & $0.75-1.39$ & 0.898 & 0.84 & $0.64-1.1$ & 0.213 & 0.86 & $0.66-1.13$ & 0.282 & 0.98 & $0.72-1.34$ & 0.922 & 0.85 & $0.63-1.14$ & 0.268 & 0.97 & $0.73-1.29$ & 0.840 & 0.89 & $0.68-1.17$ & 0.394 & 0.94 & $0.69-1.29$ & 0.717 \\
\hline rs 3136558 & 0.91 & $0.66-1.26$ & 0.577 & 0.95 & $0.72-1.26$ & 0.741 & 1.00 & $0.76-1.32$ & 0.993 & 0.85 & $0.62-1.17$ & 0.327 & 1.00 & $0.74-1.35$ & 0.993 & 0.88 & $0.66-1.18$ & 0.399 & 0.95 & $0.72-1.26$ & 0.733 & 0.91 & $0.66-1.26$ & 0.582 \\
\hline rs 1143630 & 0.92 & $0.61-1.39$ & 0.697 & 0.91 & $0.64-1.31$ & 0.627 & 0.76 & $0.52-1.11$ & 0.159 & 1.15 & $0.78-1.7$ & 0.476 & 0.72 & $0.47-1.09$ & 0.117 & 1.11 & $0.77-1.59$ & 0.568 & 0.89 & $0.62-1.27$ & 0.515 & 0.96 & $0.64-1.46$ & 0.863 \\
\hline rs 1143627 & 1.04 & $0.77-1.42$ & 0.783 & 1.11 & $0.85-1.46$ & 0.433 & 1.38 & $1.05-1.81$ & 0.023 & 0.78 & $0.57-1.06$ & 0.113 & 1.41 & $1.05-1.89$ & 0.023 & 0.86 & $0.65-1.14$ & 0.292 & 1.14 & $0.87-1.49$ & 0.341 & 1.01 & $0.74-1.38$ & 0.968 \\
\hline rsl6944 & 0.93 & $0.68-1.27$ & 0.639 & 0.89 & $0.68-1.17$ & 0.407 & 0.73 & $0.56-0.96$ & 0.026 & 1.22 & $0.9-1.66$ & 0.202 & 0.71 & $0.53-0.96$ & 0.025 & 1.12 & $0.85-1.49$ & 0.424 & 0.85 & $0.65-1.11$ & 0.239 & 1.00 & $0.73-1.37$ & 1.000 \\
\hline rs 1143623 & 0.95 & $0.69-1.31$ & 0.759 & 0.97 & 0.741 .28 & 0.821 & 0.80 & $0.6-1.06$ & 0.112 & 1.24 & $0.91-1.7$ & 0.166 & 0.86 & $0.63-1.15$ & 0.305 & 1.07 & $0.8-1.42$ & 0.649 & 0.91 & $0.7-1.2$ & 0.522 & 1.04 & $0.76-1.43$ & 0.813 \\
\hline
\end{tabular}

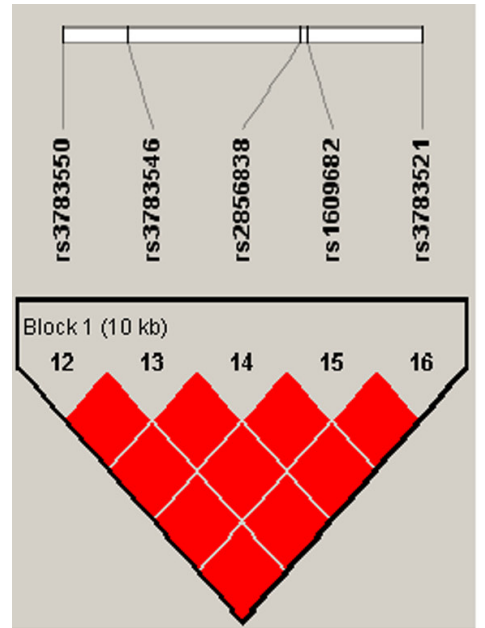

IL1A

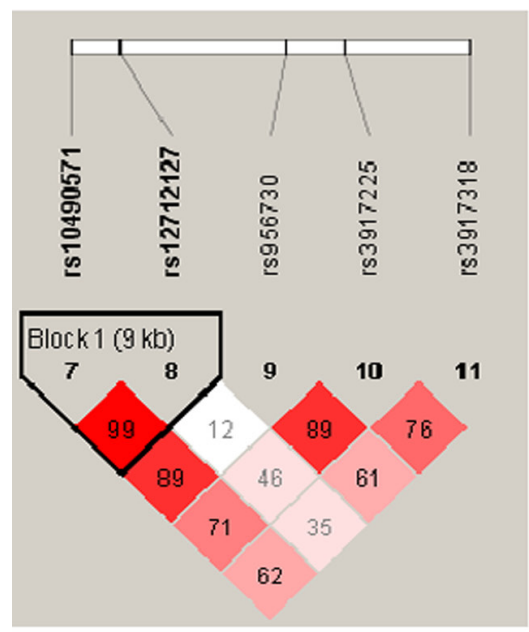

IL1R1

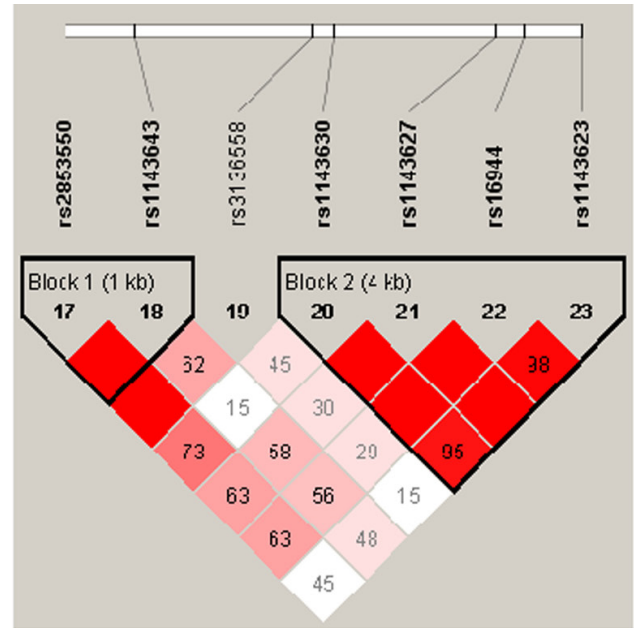

IL1B

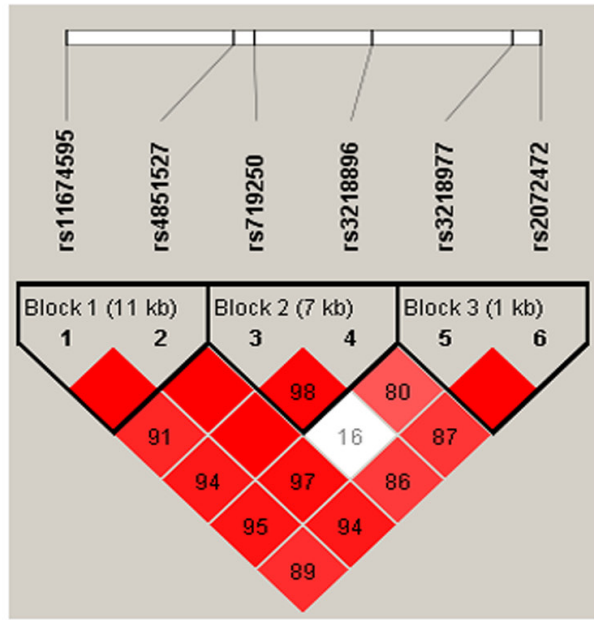

IL1R2

Figure 1: D' linkage map for the SNPs in ILIA,IL1B, IL1R1, IL1R2. 
and IL1R2), which are known as the key regulation of inflammation and immune response to multifunctional cytokines and thought that almost affects all types of cells [15]. IL-1 has been recently suggested to play a role in the development of breast cancer. IL-1A and IL-1B are produced by monocytes, macrophages and epithelial cells and are involved in various processes such as modifying host response to microbial invasion, tissue injury and inflammation [25]. Both IL-1A and IL-1B cause inflammation, but more importantly, they induce the expression of proinflammatory genes, such as cyclooxygenase type 2 , inducible nitric oxide synthase, and other cytokines/chemokines [26]. There is accumulating evidence indicating the presence of a peritumoural inflammatory infiltrate in $\mathrm{BC}$, which may reflect, at least in part, an antitumour immune response.IL-1A and IL-1B expression was increased in human breast cancer tissues. Present studies mostly focused on the associations between IL1B gene polymorphisms and BC risk, for rs1143627, in our study we found the polymorphisms was associated with BC risk before adjusted for age, however, by adjusted for age we did not found significant. Ito et al. [27] first reported rs1143627 is significantly associated with breast cancer risk (CC vs.TT: OR $=1.82$, $95 \% \mathrm{CI}=1.03-3.23)$ in the Japanese. Another casecontrol study by Liu et al. [28] supported the association in a Chinese population (CC vs. TT: adjusted OR $=1.72,95 \%$ $\mathrm{CI}=1.16-2.54)$. Hefler et al. [29] reported the rs16944 were associated with BC in European. Meanwhile, in our study also found the same result, individuals carrying " $\mathrm{A}$ " alleles to reduce the risk of breast cancer. However, up to now, there were fewer reports on the association between rs10490571 in IL1R1 polymorphisms and BC risk. Previous studies have reported with IGA nephropathy, osteoarthritis has significant correlation, in our study we found significant correlation could be found between rs10490571 polymorphism and BC risk. However, the results remained controversial partially because of small sample size, the difference in the genotype distribution by ethnicity, study design, assay characteristics and so on.

In conclusion, we showed a correlation of polymorphic markers within the proinflammatory-cytokine IL-1 gene locus with the risk in developing breast cancer.

Taken together with our finding that IL1B, IL1R1 gene three SNP are also associated with the risk for the disease, we suggest that inflammation via innate and adaptive immunity contributes to multifactorial hereditary predisposition to pathogenesis of the breast cancer.

\section{MATERIALS AND METHODS}

\section{Subjects}

A total of $530 \mathrm{BC}$ patients and 628 healthy controls were consecutively recruited between June 2012 and July 2016 at the First Affiliated Hospital of Xi'an Jiaotong
University, People's Republic of China. The controls had no family history of BC and all had been clinically confirmed and/or had a recent mammogram confirming that there was no detectable $\mathrm{BC}$ at the time of sampling. Clinicopathological parameters including age, histological subtype, TNM stage, tumor grade, lymph node metastasis, age at menarche, menopause status, number of pregnancies, number of deliveries, and family history of cancer were evaluated. Those who signed an informed consent form were asked to complete a self-administered questionnaire and to provide a $5 \mathrm{ml}$ peripheral blood sample.

In the case-control design, we selected 23 SNPs in the IL-1A, ILB, IL1R1, IL1R2 polymorphisms in BC patients from China. These SNPs from DbSNP database (http:// www.hapmap.org/index.html.en) and SNP Consortium database for analysis and each had minor allele frequency (MAF) of $>5 \%$ in Chinese Han population. DNA was isolated from Whole blood were used the GoldMag-Mini Whole Blood Genomic DNA Purification Kit (GoldMag Co. Ltd. Xi'an City, China) extracted. Genotypes for SNPs were determined by Sequenom MassARRAY .We used a NanoDrop 2000 (Gene Company Limited) were measured DNA concentrations. We used Sequenom MassARRAY Assay Design 3.0 Software to design a Multiplexed SNP MassEXTEND assay [30]. The PCR primers for each SNP are shown in Table 2. Data management and analysis was performed using the Sequenom Typer 4.0 Software [30, 31].

\section{Differences in demographic characteristics, selected variables and genotype}

Distribution, allele frequencies were analysed using the chi-square test or $t$-test. The associations between IL1 polymorphism and breast cancer risk were estimated using logistic regression to compute odds ratios (OR) and 95\% confidence intervals (CI). computing the odds ratios (ORs) and their 95\% confidence intervals (CIs) from both univariate and multivariate logistic regression analyses. Hardy-Weinberg equilibrium was tested by a goodness-offit v2 test to compare the observed genotype frequencies to the expected frequencies among the control subjects. Two sided $P$ value of less than 0.05 was considered to be significant.

\section{CONFLICTS OF INTEREST}

The authors have no conflicts of interest to report.

\section{REFERENCES}

1. Giordano SB, Gradishar W. Breast cancer: updates and advances in 2016. Curr Opin Obstet Gynecol. 2017; 29:12-17. https://doi.org/10.1097/GCO.0000000000000343.

2. Mccoy ML, Mueller CR, Roskelley CD. The role of the breast cancer susceptibility gene 1 (BRCA1) in sporadic 
epithelial ovarian cancer. Reprod Biol Endocrinol. 2003; $1: 1-5$.

3. Economopoulou P, Dimitriadis G, Psyrri A. Beyond BRCA: new hereditary breast cancer susceptibility genes. Cancer Treat Rev. 2015; 41:1-8. https://doi.org/10.1016/j. ctrv.2014.10.008.

4. Blackwood MA, Weber BL. BRCA1 and BRCA2: from molecular genetics to clinical medicine. J Clin Oncol. 1998; 16:1969-77. https://doi.org/10.1200/JCO.1998.16.5.1969.

5. Deniz M, Wiesmüller L. Breast Cancer Susceptibility Genes. 2017. https://doi.org/10.1007/978-3-662-46875-3_6619.

6. Wang S, Zhang S, Li S, Wang X, He S, Zhao Y, Fan X, Yuan F, Zhu X, Jiang Y. Analysis of SNP Network Structure Based on Mutual Information of Breast Cancer Susceptibility Genes. Springer, Singapore. 2016.

7. Smyth MJ, Cretney E, Kershaw MH, Hayakawa Y. Cytokines in cancer immunity and immunotherapy. Immunol Rev. 2004; 202:275-93. https://doi. org/10.1111/j.0105-2896.2004.00199.x.

8. El-Omar EM, Rabkin CS, Gammon MD, Vaughan TL, Risch HA, Schoenberg JB, Stanford JL, Mayne ST, Goedert J, Blot WJ, Fraumeni JF Jr, Chow WH. Increased risk of noncardia gastric cancer associated with proinflammatory cytokine gene polymorphisms. Gastroenterology. 2003; 124:1193-201. https://doi.org/10.1016/S0016-5085(03)00157-4.

9. Lu W, Pan K, Zhang L, Lin D, Miao X, You W. Genetic polymorphisms of interleukin (IL)-1B, IL-1RN, IL-8, IL-10 and tumor necrosis factor \{alpha\} and risk of gastric cancer in a Chinese population. Carcinogenesis. 2005; 26:631-36. https://doi.org/10.1093/carcin/bgh349.

10. Eso Y, Takai A, Matsumoto T, Inuzuka T, Horie T, Ono K, Uemoto S, Lee K, Edelmann W, Chiba T, Marusawa $\mathrm{H}$. MSH2 dysregulation is triggered by proinflammatory cytokine stimulation and is associated with liver cancer development. Cancer Res. 2016; 76:4383-93. https://doi. org/10.1158/0008-5472.CAN-15-2926.

11. Li QY, Shi Y, Huang DH, Yang T, Wang JH, Yan GH, Wang HY, Tang XJ, Xiao CY, Zhang WJ, Zhang M, Wang L, Gong Y, et al. Cytokine-induced killer cells combined with dendritic cells inhibited liver cancer cells. Int J Clin Exp Med. 2015; 8:5601-10.

12. Pan Y, Wu Y, Ji J, Cai H, Wang H, Jiang Y, Sang L, Yang J, Gao Y, Liu Y, Yin L, Zhang LI. Effect of cytokine-induced killer cells on immune function in patients with lung cancer. Oncol Lett. 2016; 11:2827-34.

13. Banzola I, Mengus C, Wyler SF, Sais G, Keller EX, Poyet C, Eberli D, Sulser T, Spagnoli GC, Provenzano M. The impact of the pro-inflammatory cytokine TNF- $\alpha$ in prostate cancer development. International Congress of Immunology. Conference: International Congress of Immunology, At Melbourne. European Journal of Immunology. 2016; 46:375.
14. Antoneeva II, Abakumova TV, Dolgova DR, Gening TP, Pirmamedova SS, Myasnikova DF, Gening SO. Cytokine Status of Serum in Ovarian Cancer Patients with Different Tumor Neoadjuvant Chemotherapy Response. Anticancer Agents Med Chem. 2017; 17:1251-55. https://doi.org/10.2 174/1871520617666170103100350.

15. Bensen JT, Dawson PA, Mychaleckyj JC, Bowden DW. Identification of a novel human cytokine gene in the interleukin gene cluster on chromosome 2q12-14. J Interferon Cytokine Res. 2001; 21:899-904. https://doi. org/10.1089/107999001753289505.

16. Dinarello CA. Biologic Basis of Interleukin-1. Disease. 1996.

17. Elaraj DM, Weinreich DM, Varghese S, Puhlmann M, Hewitt SM, Carroll NM, Feldman ED, Turner EM, Alexander HR. The role of interleukin 1 in growth and metastasis of human cancer xenografts. Clin Cancer Res. 2006; 12:1088-96. https://doi.org/10.1158/1078-0432. CCR-05-1603.

18. Gemma A, Takenaka K, Hosoya Y, Matuda K, Seike M, Kurimoto F, Ono Y, Uematsu K, Takeda Y, Hibino S, Yoshimura A, Shibuya M, Kudoh S. Altered expression of several genes in highly metastatic subpopulations of a human pulmonary adenocarcinoma cell line. Eur J Cancer. 2001; 37:1554-61. https://doi.org/10.1016/ S0959-8049(01)00154-X.

19. Kurzrock R. Cytokine deregulation in cancer. Biomed Pharmacother. 2001; 55:543-47. https://doi.org/10.1016/ S0753-3322(01)00140-8.

20. Akisik E, Dalay N. Functional polymorphism of thymidylate synthase, but not of the COMT and IL-1B genes, is associated with breast cancer. J Clin Lab Anal. 2007; 21:97-102. https://doi.org/10.1002/jcla.20139.

21. Balasubramanian SP, Azmy IA, Higham SE, Wilson AG, Cross SS, Cox A, Brown NJ, Reed MW. Interleukin gene polymorphisms and breast cancer: a case control study and systematic literature review. BMC Cancer. 2006; 6:188. https://doi.org/10.1186/1471-2407-6-188.

22. de Jong MM, Nolte IM, te Meerman GJ, van der Graaf WT, Oosterwijk JC, Kleibeuker JH, Schaapveld M, de Vries EG. Genes other than BRCA1 and BRCA2 involved in breast cancer susceptibility. J Med Genet. 2002; 39:225-42. https://doi.org/10.1136/jmg.39.4.225.

23. Kumar S, Kishimoto H, Chua HL, Badve S, Miller KD, Bigsby RM, Nakshatri H. Interleukin-1 alpha promotes tumor growth and cachexia in MCF-7 xenograft model of breast cancer. Am J Pathol. 2003; 163:2531-41. https://doi. org/10.1016/S0002-9440(10)63608-5.

24. Speirs V, Kerin MJ, Newton CJ, Walton DS, Green AR, Desai SB, Atkin SL. Evidence for transcriptional activation of ERalpha by IL-1beta in breast cancer cells. Int J Oncol. 1999; 15:1251-54. 
25. Lee S, Kim E, Jhun H, Hong J, Kwak A, Jo S, Bae S, Lee J, Kim B, Lee J, Youn S, Kim S, Kim M, et al. Proinsulin Shares a Motif with Interleukin- $1 \alpha$ (IL-1 $\alpha)$ and Induces Inflammatory Cytokine via Interleukin-1 Receptor 1. J Biol Chem. 2016; 291:14620-27. https://doi.org/10.1074/jbc. M116.731026.

26. Kumar M, Roe K, Nerurkar PV, Orillo B, Thompson KS, Verma S, Nerurkar VR. Reduced immune cell infiltration and increased pro-inflammatory mediators in the brain of Type 2 diabetic mouse model infected with West Nile virus. J Neuroinflammation. 2014; 11:80. https://doi. org/10.1186/1742-2094-11-80.

27. Ito LS, Iwata H, Hamajima N, Saito T, Matsuo K, Mizutani M, Iwase T, Miura S, Okuma K, Inoue M, Hirose K, Tajima $\mathrm{K}$. Significant reduction in breast cancer risk for Japanese women with interleukin 1B $-31 \mathrm{CT} / \mathrm{TT}$ relative to $\mathrm{CC}$ genotype. Jpn J Clin Oncol. 2002; 32:398-402. https://doi. org/10.1093/jjco/hyf081.

28. Liu J, Zhai X, Jin G, Hu Z, Wang S, Wang X, Qin J, Gao J, Ma H, Wang X, Wei Q, Shen H. Functional variants in the promoter of interleukin-1beta are associated with an increased risk of breast cancer: a case-control analysis in a Chinese population. Int J Cancer. 2006; 118:2554-58. https://doi.org/10.1002/ijc.21652.

29. Hefler LA, Grimm C, Lantzsch T, Lampe D, Leodolter S, Koelbl H, Heinze G, Reinthaller A, Tong-Cacsire D, Tempfer C, Zeillinger R. Interleukin-1 and interleukin-6 gene polymorphisms and the risk of breast cancer in caucasian women. Clin Cancer Res. 2005; 11:5718-21. https://doi.org/10.1158/1078-0432.CCR-05-0001.

30. Gabriel S, Ziaugra L, Tabbaa D. SNP genotyping using the Sequenom MassARRAY iPLEX platform. Current Protocols in Human Genetics. 2009; 2:Unit 2.12. https:// doi.org/10.1002/0471142905.hg0212s60.

31. Thomas RK, Baker AC, Debiasi RM, Winckler W, Laframboise T, Lin WM, Wang M, Feng W, Zander T, MacConaill L, Lee JC, Nicoletti R, Hatton C, et al. Highthroughput oncogene mutation profiling in human cancer. Nat Genet. 2007; 39:347-51. https://doi.org/10.1038/ ng1975. 